\title{
Should subclinical hypothyroidism in elderly patients be treated?
}

Gussekloo J, van Exel E, de Craen AJM, Meinders AE, Frölich M, Westendorp RGJ. Thyroid status, disability and cognitive function, and survival in old age. JAMA 2004;292:2591-9.

Background: Subclinical hypothyroidism is defined as a normal serum free thyroxine level combined with an elevated thyroid-stimulating hormone (TSH) level. Symptoms include constipation, dry skin, cognitive dysfunction and depression. This syndrome is common among elderly people, and among older women the prevalence may be as high as $20 \%$. It has been recommended that subclinical hypothyroidism warrants treatment in elderly patients. ${ }^{1,2}$

Design: This population-based prospective study included all patients aged 85 years living in Leiden, the Netherlands. A total of 599 patients $(87 \%$ of those approached) agreed to participate. Thyroid status was assessed at baseline and again at the age of 88. Patients with overt thyroid disease were referred to their family physicians for treatment, and patients with subclinical hypothyroidism were followed up without therapy. At annual visits, until participants reached 89 years, investigators evaluated activities of daily living and cognitive and affective function.

Results: At baseline and during follow-up, there was no association between subclinical or overt hypothyroidism and lessened physical function, depressive symptoms or cognitive loss. In fact, increasing levels of TSH were associated with lower mortality (hazard ratio [HR] $0.77,95 \%$ confidence interval [CI] $0.63-0.94$ per 2.71 $\mathrm{mIU} / \mathrm{L}$ increase), and higher levels of free thyroxine were associated with increased mortality (HR 1.16, 95\% CI 1.04-1.30 per $2.7 \mathrm{pmol} / \mathrm{L}$ increase) after adjusting for sex, disability and health status. At the end of follow-up, no patient with subclinical hypothyroidism at baseline had progressed to overt hypothyroidism.

Commentary: The results of studies of younger patients have suggested that subclinical hypothyroidism may be associated with a number of abnormalities, including depression, memory problems, elevated lipid levels, cardiac dysfunction and an increased rate of cardiovascular events. ${ }^{1}$ Results of intervention studies with younger subjects suggest that these abnormalities may be reversed to some extent by thyroid hormone, although the literature is far from clear in this regard.

In contrast, studies of geriatric populations have not consistently shown associations between depression, memory loss or other symptoms and subclinical hypothyroidism. Despite this, some groups have recommended that all elderly patients with subclinical hypothyroidism and a TSH level greater than $10 \mathrm{mIU} / \mathrm{L}$ receive hormone replacement therapy (HRT) and that HRT be considered for older people with compatible symptoms and a TSH level between 5 and $10 \mathrm{mIU} / \mathrm{L}$. ${ }^{1,2}$ To date, no randomized controlled trials have provided evidence to support these recommendations, and there is reason to suspect that they may be flawed. It is known that restriction in energy intake, with its associated reduction in metabolic rate, results in increased longevity in animal models of aging. Administration of thyroid hormone could theo- retically accelerate the aging process by increasing metabolic rate. In addition, age-related hormone deficiencies (e.g., growth hormone) are not necessarily associated with poor outcomes. In fact, restoring hormone levels in older patients to those of younger patients may have adverse consequences. ${ }^{3}$

Finally, very old patients (e.g., > 85 years) may be biologically different from moderately older patients (e.g., 60-70 years). For example, octogenarians with higher blood pressure values tend to live longer than those with lower values. ${ }^{4}$ Consequently, the wisdom of treating hypertension and other abnormalities in very old patients has been called into question.

Practice implications: Although large randomized trials are needed to confirm this, the results of the study suggest that HRT should not be used to treat subclinical hypothyroidism in patients older than 85 years, because it may cause harm.

\section{Graydon S. Meneilly \\ Professor and Head \\ Department of Medicine \\ University of British Columbia \\ Vancouver, BC}

\section{References \\ 1. Surks MI, Ortiz E, Daniels GH, Sawin CT, Col NF, Cobin RH, et al. Subclinical thyroid disease, scientific review and guidelines for diagnosis and management. FAMA 2004;291(2): 228-38. \\ 2. Gharib H, Tuttle RM, Baskin HJ, Fish LH, Singer PA, McDermott MT. Subclinical thyroid dysfunction: A joint statement on management from the American Association of Clinical Endocrinologists, the Ameri- can Thyroid Association, and the En- docrine Society. 7 Clin Endocrinol Metab 2005;90:581-5. \\ 3. Harman SM, Blackman MR. Use of growth hormone for prevention or treatment of effects of aging. 7 Geron- tol 2004;59A:652-8. \\ 4. Goodwin JS. Embracing complexity: a consideration of hypertension in the very old. 7 Gerontol 2003;58A:653-8.}

